\title{
Shurun-Urgun Highway Composite Steel Bridge Elastomeric Bearings Under Seismic Force
}

\author{
Ahmad Zubair Rahimi
}

Faculty of construction, department of Transportation Engineering, Kabul Polytechnic University, Kabul, Afghanistan

\section{ARTICLE INFO}

\section{Keywords:}

Elastomric bearing

Bridge seismic design

Seismic behavior

Bearing parameters

Composite steel bridge

USGS maps

Fundament period

Afghanistan seismic maps

Seismic hazards

\begin{abstract}
This study examines the parameters of Elastomeric Bearing (EB) for affecting the seismic design and behavior for Shurun-Urgun Composite-Steel Bridge is located in Paktia province in eastern part of Afghanistan. Laminated elastomeric bearings used in addition to provide connection between bridge superstructure and substructure, reduce the response of bridge during an earthquake by increasing fundamental period of vibration of bridge, and might reduce the acceleration of superstructure and inertia force passed to the substructure. As an analysis has been done using computer models for two type of piers (tall \& short) for similar bridge with or without elastomeric bearing pads and a manually calculation for this numerical investigation to determine the magnitude of forces, displacements and deformations. USGS seismic hazard maps for Afghanistan, and referred to AASHTO, FHWA, and Caltrans manuals where needed.
\end{abstract}

\section{Introduction}

The mountainous heart of Asia-Afghanistan is shaped by tectonically active Alpine-Himalayan orogenic belt that in reflex to the collision between the Indian plate, Arabian plate, and Eurasian plate in Late Paleocene to current period (fig. 1) (Ruleman, \& others, 2007). In such geologically hazardous region with annually moderate to strong earthquakes cause significant damages and fatalities, earthquakes pose a real significant menace to the people and reconstruction of Afghanistan. Now by the efforts of the U.S. Geological Survey (USGS) a series of probabilistic seismic hazard maps to predict the frequency and strength of ground shaking quantity throughout the country (Boyd, \& others, 2007; Caltrans, 1994).

Composite bridge as a perfect combination of steel girder with concrete slab is easy to erect and economic with lighter structural loads on the piers and foundations compared to the construction of concrete girder commonly used in short-to-medium span (Chen \& Duan, 2000). Suran-Urgun Highway Composite-Steel Bridge is supported by laminated (steel - reinforced) elastomeric bearings (fig. 3). Seismic isolation bearings used may lower the response of bridge during an earthquake. Isolation bearings should be stiff under service conditions, and flexible under seismic loads. This is as isolators transmit service loads to the bridge's piers without developing harmful overstress with minimum amount of movement, but as a flexible layer between superstructure and substructure protect structure from damaging action of earthquake by partially decoupling with low stiffness and high damping characteristics. In addition, elastomeric bearings would permit lateral movement due to temperature change, traffic movements, wind, shrinkage, creep, foundation movement, seismic actions, dynamic forces and vibrations. Moreover, elastomeric bearings extend the life of bridge by reducing the wear and tear of the bridge materials - much like the shoes allow human beings walk long distances.

* Corresponding Author E-Mail Address: azrahimi10@gmail.com 
The superstructure essentially acts like a rigid body, thus reducing the inter-story movement. When the period is increased, pseudo-acceleration is decreased and hence the force in the structure gets reduced. However, the displacement of the system increases drastically. Flexibility in elastomeric isolation systems is provided by elastomeric bearings (laminated rubber bearings reinforced with steel plates). Energy-dissipation capacity is provided by inherent damping capacity of the rubber, as in high-damping elastomeric bearings (AASHTO, 2012; Caltrans, June 1994 \& FHWA, 2006).

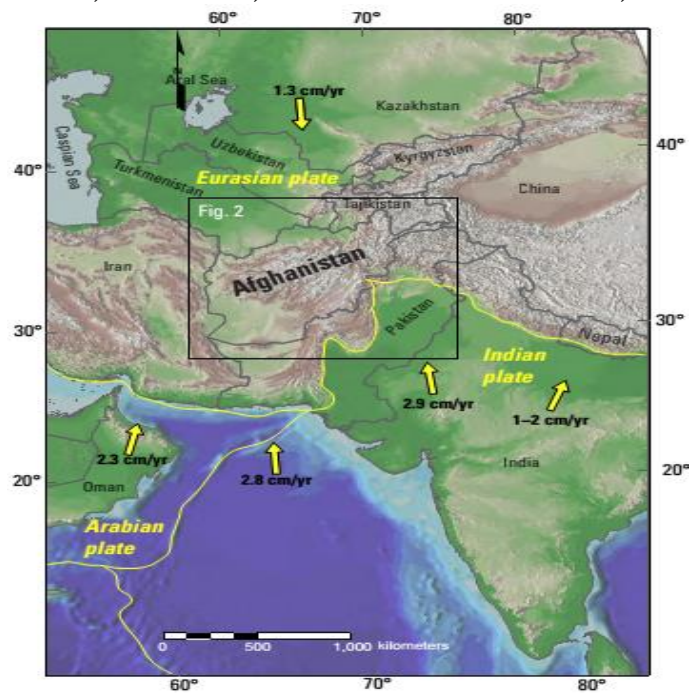

Figure 1. Location of study area in the greater Alpine Himalaya orogenic belt of Asia. Vectors show relative plate motions and velocities between the Indian, Eurasian, and Arabian plates (plate boundaries shown and labeled in yellow). Plate velocities from (Jade, 2004; Bird, 2003; Vernant et al., 2004; and Sella et al., 2002).

Figure 2. Box area shows area of study

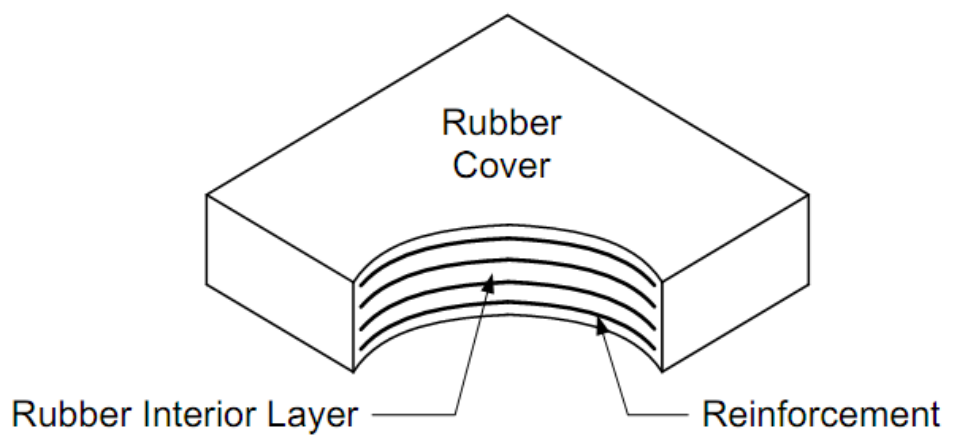

Figure 3. Laminated (Steel Reinforced) Elastomeric Bearing

\section{General Modeling Assumption}

Dynamic analysis of the bridge exposed to earthquakes geometric configuration, mass and stiffness of bridge components and mechanical properties of elastomeric bearing are included in computer modeling. Link elements in a bridge model link elements present elastomeric bearing where their properties are defined as hard spring under compression and weak spring under shear. Elastomer flexibility gives bridge maximum longitudinally release and blocked transversely. Fundamental period, shifts and variations in internal force distribution in the bridge members are expected.

\section{Example Bridge}

The plotted dimensions belong to a three equally (30m) spans of real constructed Shurun-Urgun Highway Composite Steel Bridge (fig. 5a, b \& c), which is located in fourth earthquake zone 
in eastern part of Afghanistan, with $6.5 \mathrm{~m}$ height piers. Elastomeric bearing pads are supporting deck on the substructure. Computer models using SAP2000 have been performed for analyses with a hand calculation and the numerical results are compared.

Structural analysis is carried out using three-dimensional multi-mode model of bridge and simplified model (SDOF-system: using bridge's rigidity and mass) considering and ignored the elastomeric bearing pads. The processes repeated on the bridge with taller piers and then result from simple analysis (manually calculation) will be compared to find out the impact of elastomeric bearings on seismic response of bridge. Only half of superstructure weight is considered on pier.

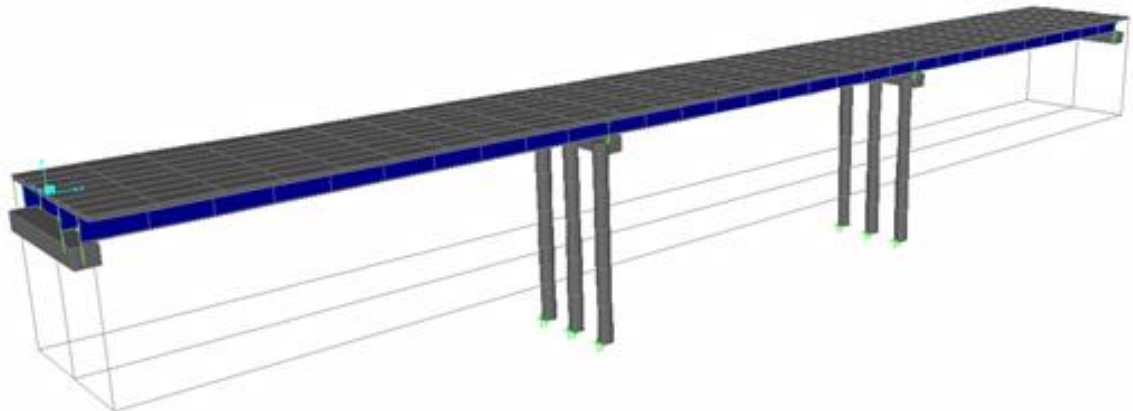

Figure 4. Bridge 3D Model

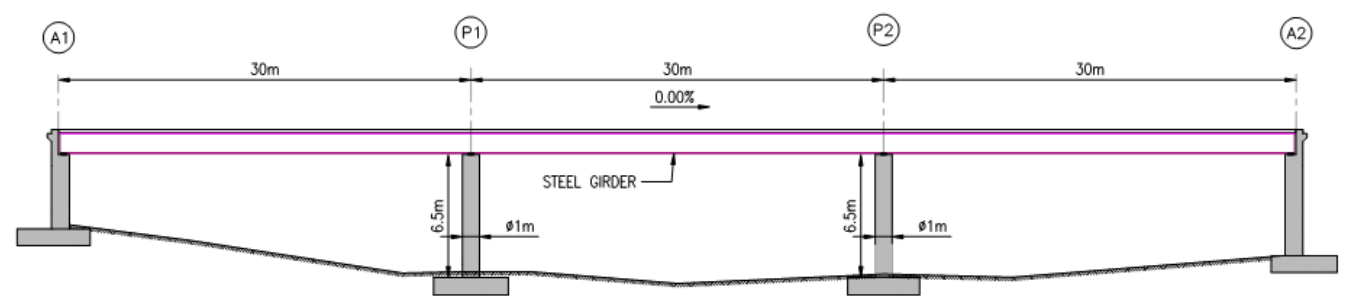

Figure 5a. Bridge Longitudinal Section

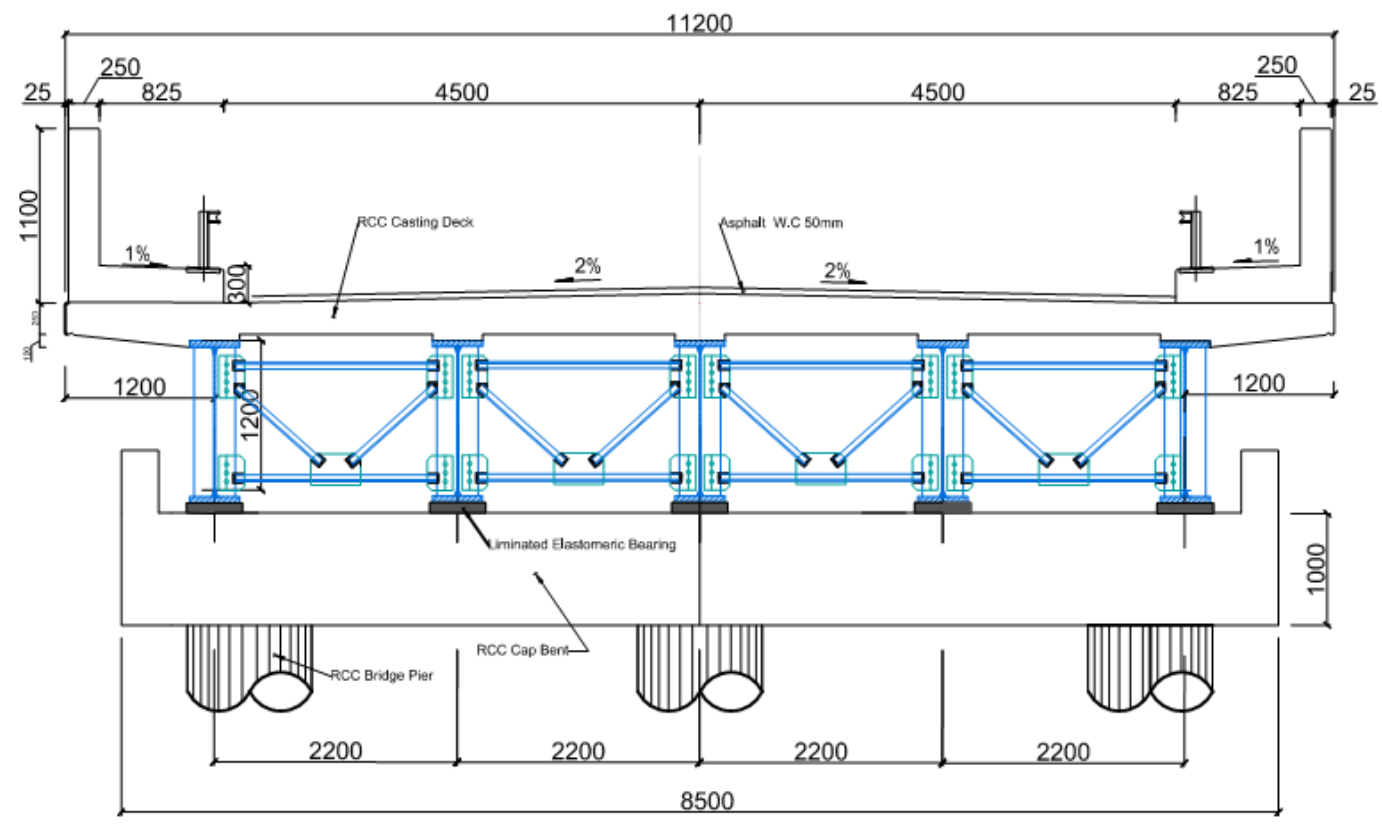

Figure 5b. Bridge Vertical Section of Deck with Steel Girder 


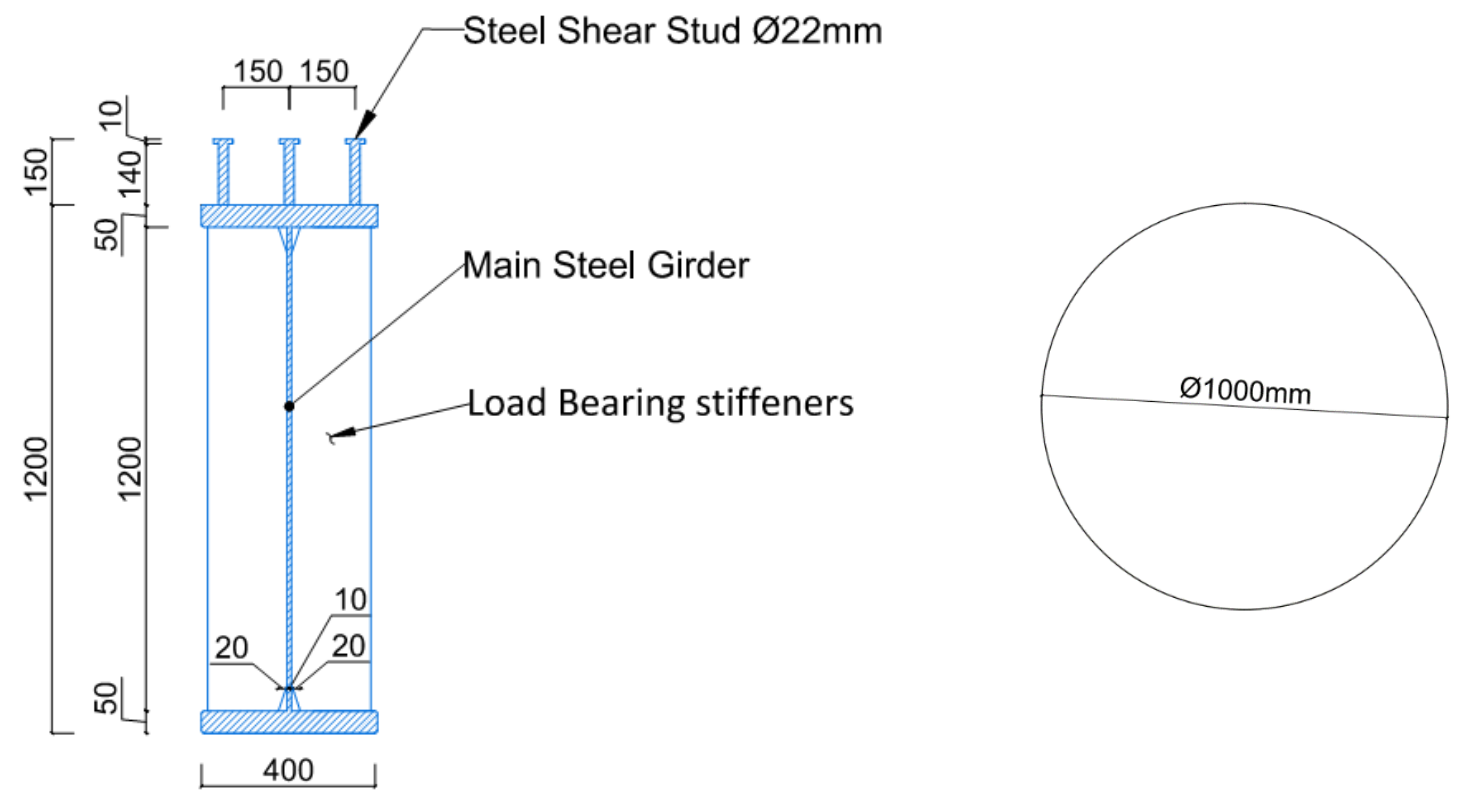

Figure 5c. Shurun-Urgun Bridge Cross sections of columns and steel girders

\section{a. Seismic Input}

Table 1.

Seismic Input for Response Spectrum Design (LRFD)

\begin{tabular}{ll}
\hline$S_{s}$ (short period acceleration) & $0.9 \mathrm{~g}$ \\
$S_{l}$ (long period acceleration) & $0.25 \mathrm{~g}$
\end{tabular}

Soil Type

Fa (Short Period Soil Coef.)

Fv (1-sec. Period Soil Coef.)

$S_{D S}$ (acceleration coef at 0.2 sec. period)

$S_{D 1 \text { (acceleration coef at } 1.0 \mathrm{sec} \text {. period) }}$

Seismic Performance Zone

Importance Category

Ts

T0

Less than $\mathrm{T}_{0}, \mathrm{Sa}$

Greater than Ts, Sa
Class C (with soft to medium-stiff clays) and sand

1.04

1.35

$0.936 \mathrm{~g}$

$0.6075 \mathrm{~g}$

$4(0.50<$ SD1), [TABLE 3..15.2-1]

Essential

$S_{D 1 /} S_{D S}=0.649$

$0.2 \times \mathrm{Ts}=0.1298$

$0.6 \frac{S_{D S}}{T_{0}} T+0.4 S_{D S}=7.211 T+0.374$

$0.936 / \mathrm{T}$ 


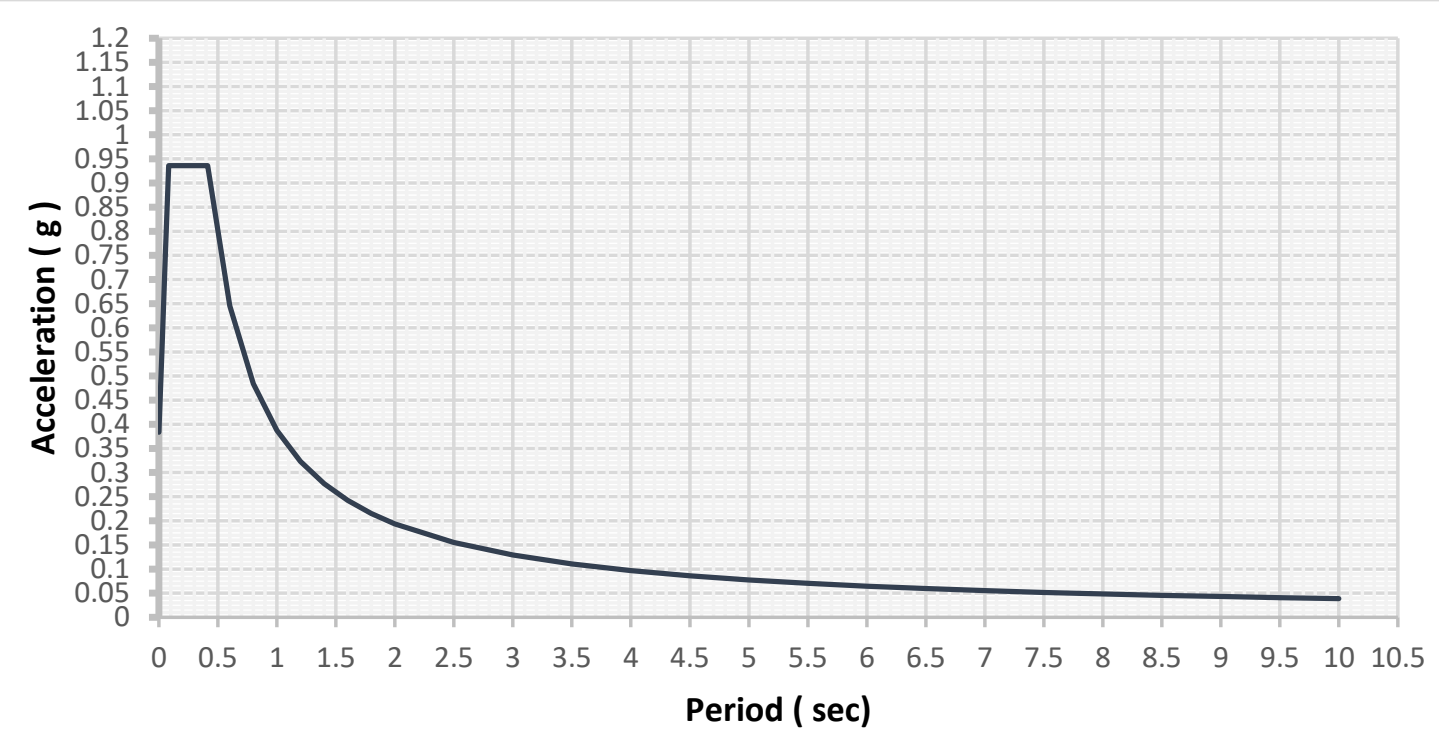

Figure 6. Seismic Response Spectrum Acceleration Graph

\section{b. Elastomeric Bearings}

The type of elastomeric bearing is used shown in figure 7. Link elements show the elastomeric bearings in structural analysis and their all properties listed in table 2. Their stiffness is calculated below where $K_{H}, K_{V}$ and $K_{\theta}$, are the lateral, vertical and rotational stiffness's of the elastomeric bearing pads and figure 8 illustrates elastomeric bearings deformations under loads (Caltrans, Bridge Design Specification, April 2000).

Table 2.

Properties of elastomeric bearing

\begin{tabular}{lc}
\hline Descriptions & Values $(\mathbf{c m})$ \\
\hline Elastomer Bearing Length L $(\mathrm{cm})$ & 35 \\
Elastomer Bearing Width W $(\mathrm{cm})$ & 45 \\
Elastomer Bearing Height H $(\mathrm{cm})$ & 8.5 \\
Total elastomer thickness $\mathrm{h}_{\mathrm{r}}(\mathrm{cm})$ & 6.1 \\
Thickness of one elastomer layer $\mathrm{h}_{\mathrm{ri}}(\mathrm{cm})$ & 0.8 \\
Thickness of one steel reinforcement layer $\mathrm{h}_{\mathrm{s}}(\mathrm{cm})$ & 0.3 \\
Elastomer gross plan area A $(\mathrm{cm} 2)$ & 1575 \\
Elastomer moment of inertia I $(\mathrm{cm} 4)$ & 1600 \\
Shape factor $(\mathrm{S})$ & 12.3 \\
Shear modulus of the elastomeric bearing $(\mathrm{G})$ & $0.68 \mathrm{Mpa}$ \\
Amount of bearing n (at end of girder) & 3 \\
\hline
\end{tabular}
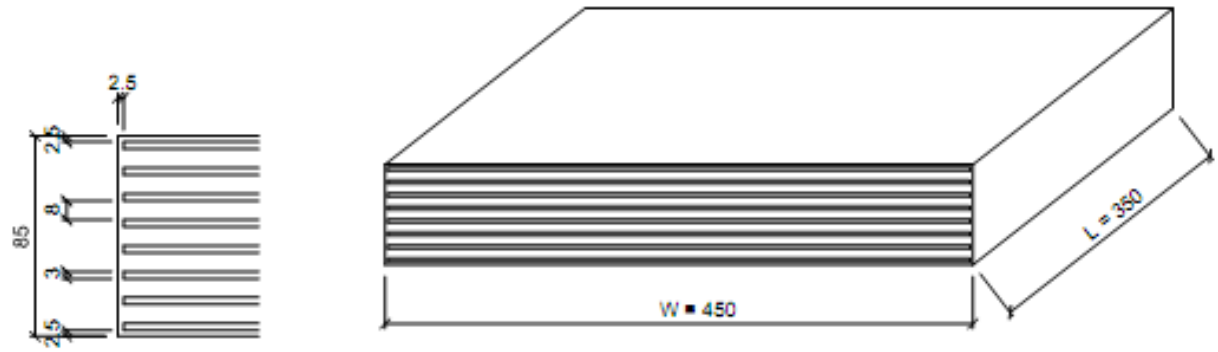

\section{ELASTOMERIC BEARING}

DIMENSIONS in mm.

Figure 7. Elastomeric Bearing Dimensions 


$$
\begin{aligned}
& K_{H}=\frac{G \cdot A}{H_{r}}=\frac{680 \cdot 1575}{0.061}=1755 \mathrm{KN} / \mathrm{m} \\
& K_{V}=\frac{E \cdot A}{H}=\frac{617263 \cdot 1575}{0.085}=1143752 \mathrm{KN} / \mathrm{m} \\
& K_{\theta}=\frac{E \cdot A}{H_{r}}=\frac{617263 \cdot 1575}{0.061}=16270 \mathrm{KN} / \mathrm{m}
\end{aligned}
$$

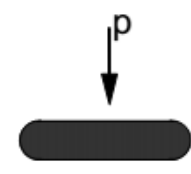

Vertical Deflection

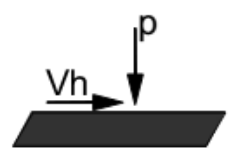

Vertical and Horizontal Deflection

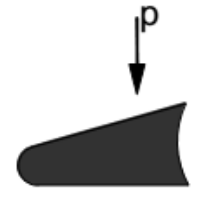

Vertical and Rotational Deflection

Figure 8. Deformation of Elastomeric Bearing under Gravity Loads

\section{c. Structural Model Without Elastomeric Bearing}

Supposing the bridge without its elastomeric bearing resistance entirely at seismic loading (modeling as simple fixed or sliding hinges) analysis and design. Connection between superstructure and substructure is free to move at abutments and top of the pier. Abutments carry only vertical loads and only pier inertia resists longitudinal movement.

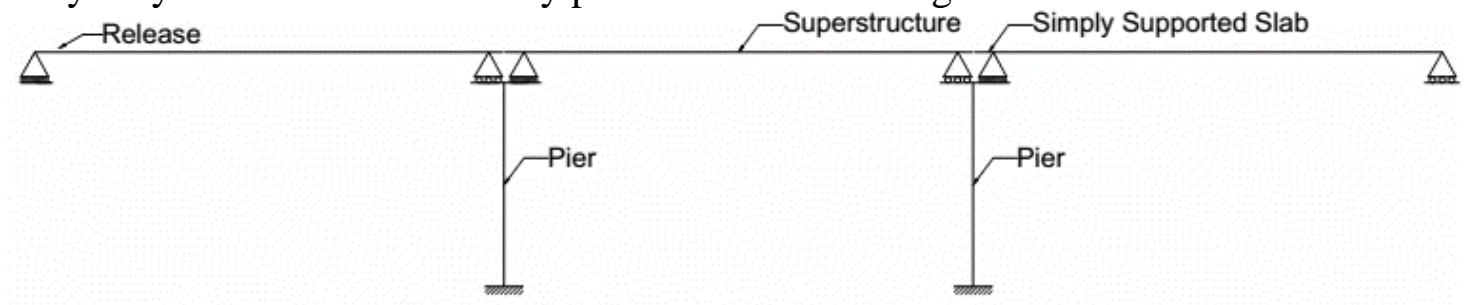

Figure 9. Bridge Model without Elastomeric Bearings

\section{d. Structural Model with Elastomeric Bearing}

In this case, we suppose elastomeric bearings as connection between superstructure and substructure of the bridge that represented as link elements in computer analysis in (CSI, SAP2000) to connect superstructure with substructure (piers and abutments). These adjustments in stiffness would influence the fundamental period of the bridge earthquake load as a result the bridge design.

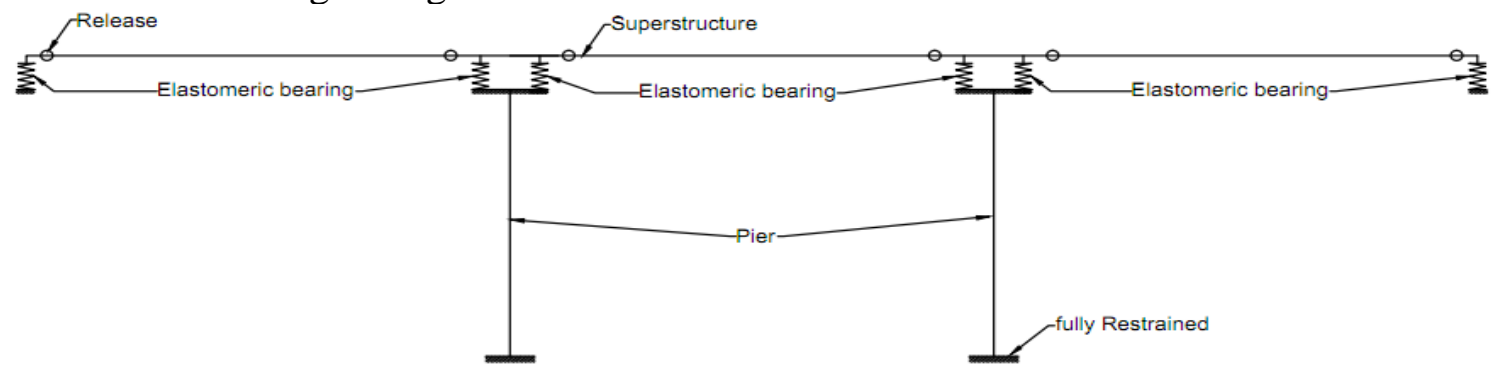

Figure 10. Bridge Model with Elastomeric Bearings 


\section{e. Simplified Model}

This model analyzed by using an equivalent SDOF system. Piers represent by one frame element and elastomers on the top of pier model as a link element where elastomeric pads on the abutment modeled as springs. Significant part of mass participation at seismic case comes from bridge Superstructure (Caltrans, November 2010).

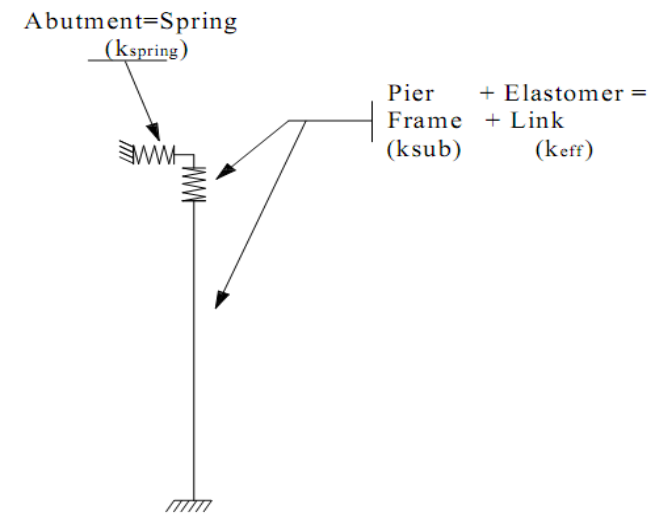

Figure 11. Bridge Simplified Model

\section{f. Analysis (Manually Calculations)}

All of the three bridge models are analyzed with SAP2000 software. Fundamental periods in the bridge longitudinal direction, internal forces, and displacements obtained from each model will be given for comparison purposes in (table 4). In an alternative analysis (manually analysis for the bridge with short piers), the period of bridge will be found using structure's rigidity, pier stiffness, total stiffness of elastomer and mass (table 3) on the pier of the bridge (Caltrans(Metric), October 1995):

Table 3.

Weight of Bridge for Seismic Calculations

\begin{tabular}{cclcc}
\hline No & Name & \multicolumn{1}{c}{ Description } & Value & Unit \\
\hline a. & Deck & Slab thickness & 61.2 & $\mathrm{KN} / \mathrm{m}$ \\
b. & Steel Girder & Four I- beam steel girders & 11.605 & $\mathrm{KN} / \mathrm{m}$ \\
& & length & 8.5 & $\mathrm{~m}$ \\
& & Width & 1.2 & $\mathrm{~m}$ \\
c. & \multirow{2}{*}{ Pier Cap } & Height & 1 & $\mathrm{~m}$ \\
& & No. of caps & 2 & \\
& & Total weight of caps & 489.6 & $\mathrm{KN}$ \\
& & Diameter & 1 & $\mathrm{~m}$ \\
& & Column height & 6.5 & $\mathrm{~m}$ \\
d. & Columns & Total No. of columns & 6 & \\
& & Total weight of columns & 735.429 & $\mathrm{KN}$ \\
& & Length of Bridge & 90 & $\mathrm{~m}$ \\
e. & $\mathbf{W}$ (super) & Total weight of superstructure & $\mathbf{6 5 5 2 . 4 5 0}$ & $\mathbf{K N}$ \\
f. & $\mathbf{W}$ (sub) & Total weight of substructure & $\mathbf{1 2 2 5 . 0 2 9}$ & $\mathbf{K N}$ \\
\hline
\end{tabular}




$$
\begin{aligned}
& k_{\text {pies }}=2 \cdot \frac{3 E I}{H^{3}}=2 \cdot \frac{3 \cdot 25 \cdot 10^{6} \cdot 0.049}{6.5^{3}}=26763.769 \mathrm{KN} / \mathrm{m} \\
& n \cdot k_{\text {eff }}=n \cdot \frac{G_{\text {els }} A}{H_{\text {els }}}=16 \cdot \frac{690 \cdot 0.1575}{0.061}=28091.803 \mathrm{KN} / \mathrm{m}
\end{aligned}
$$

The effective linear stiffness:

$$
\begin{aligned}
& K_{\text {eff }}=n \cdot \frac{k_{\text {eff }} \cdot k_{\text {pies }}}{k_{\text {pies }}+k_{\text {eff }}}=\frac{26763.769 \cdot 28091.803}{26763.769+28091.803} \\
& K_{\text {eff }}=13705.855 \mathrm{KN} / \mathrm{m}
\end{aligned}
$$

Stiffness of elastomeric bearing on abutments:

$$
\begin{aligned}
& k_{\text {spring }}=n \cdot k_{\text {eff }}=n \cdot \frac{G_{\text {els }} A}{H_{\text {els }}}=8 \cdot \frac{690 \cdot 0.1575}{0.061} \\
& k_{\text {spring }}=14045.902 \mathrm{KN} / \mathrm{m}
\end{aligned}
$$

Total longitudinal stiffness:

$$
\begin{aligned}
& K_{\text {Tot }}=\sum\left(K_{\text {eff }}+k_{\text {spring }}\right)=\sum(13705.855+14045.902) \\
& K_{\text {Tot }}=27751.775 \mathrm{KN} / \mathrm{m}
\end{aligned}
$$

Participated mass at the seismic case:

$$
\begin{aligned}
& \mathrm{M}_{\text {Tot }}=M_{\text {super }}+0.5 M_{\text {sub }}=\frac{6552.450+612.513}{9.81} \\
& \mathrm{M}_{\text {Tot }}=730.373 \text { Ton }
\end{aligned}
$$

Fundamental period of bridge:

$T=2 \pi \sqrt{\frac{\mathrm{M}_{\text {Tot }}}{K_{\text {Tot }}}}=2 \pi \sqrt{\frac{730.373}{27751.775}}=1.019 \mathrm{sec}$

\section{Result Collation}

The following observations can be made from two bridges analyses with the same superstructure but one is taller and less stiff to show the effect of substructure's rigidity on seismic response. Results achieved from each bridge analysis are summarized in table 4. In the table $\mathrm{T}$ refers to period of bridge, $\mathrm{M}$ is moment at pier bottom, $\mathrm{V}$ is shear force at one pier, $\mathrm{V}_{\mathrm{K}}$ is lateral force at one abutment, $\mathrm{d}_{\text {sub }}$ is displacement of substructure, $\mathrm{d}_{\mathrm{els}}$ is displacement of elastomeric bearing. 
Table 4.

Bridge Computer Models Analyses Numerical Results

\begin{tabular}{cccccccc}
\hline & \multicolumn{3}{c}{ Bridge (H=6.5m Height) } & & \multicolumn{3}{c}{ Bridge (H=13m Height) } \\
\cline { 2 - 4 } \cline { 6 - 8 } \cline { 6 - 8 } & Without & Elastomer & Simplified & & Without & Elastomer & Simplified \\
\hline $\mathrm{T}(\mathrm{sec})$ & 0.758 & 1.019 & 1.019 & & 0.981 & 1.178 & 1.178 \\
$\mathrm{M}(\mathrm{KN} . \mathrm{m})$ & 6030 & 823 & 836 & & 1748 & 1569 & 1582 \\
$\mathrm{~V}(\mathrm{KN})$ & 7370 & 2552 & 2552 & & 3073 & 2440 & 2440 \\
$V_{k}(\mathrm{KN})$ & - & 576 & 693 & & - & 387 & 387 \\
$\sum \mathrm{V}(\mathrm{KN})$ & 14740 & 6257 & 6490 & & 6146 & 5655 & 5655 \\
$d_{\text {sub }}(\mathrm{cm})$ & 3.246 & 1.672 & 1.672 & & 7.517 & 4.632 & 4.633 \\
$d_{\text {els }}(\mathrm{cm})$ & - & 7.853 & 7.853 & & - & 11.861 & 11.860 \\
$\sum \mathrm{d}(\mathrm{cm})$ & 3.246 & 9.524 & 9.525 & & 7.517 & 16.494 & 16.493 \\
\hline
\end{tabular}

\section{4a. Tall Bridge $(\mathrm{H}=13 \mathrm{~m})$}

Fundamental period of tall bridge with elastomeric bearings is taller than the same bridge height without elastomeric bearings. Bridge period with elastomeric bearings and simplified method are the same. Elastomer increased bridge period about. Base shear in model with elastomer is shorter. Moment value in bridge with elastomer is noticeably low. Elastomers reduce the displacement of substructure about $2.885 \mathrm{~cm}$.

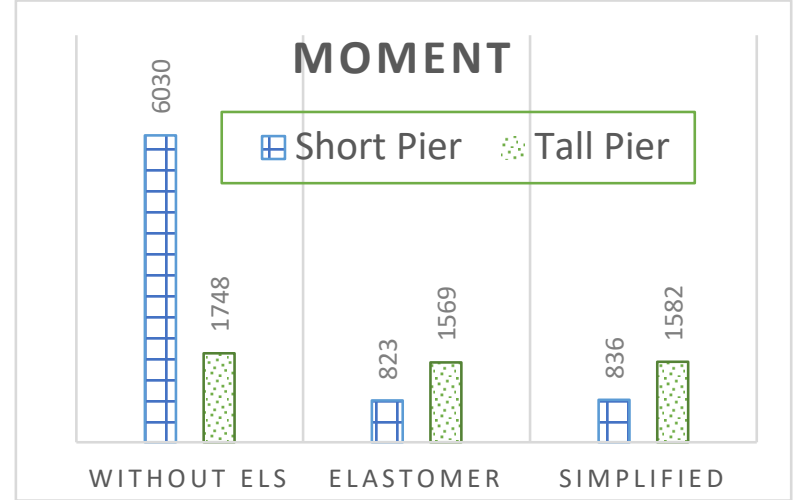

Figure 12a. Moment Comparison at the Piers

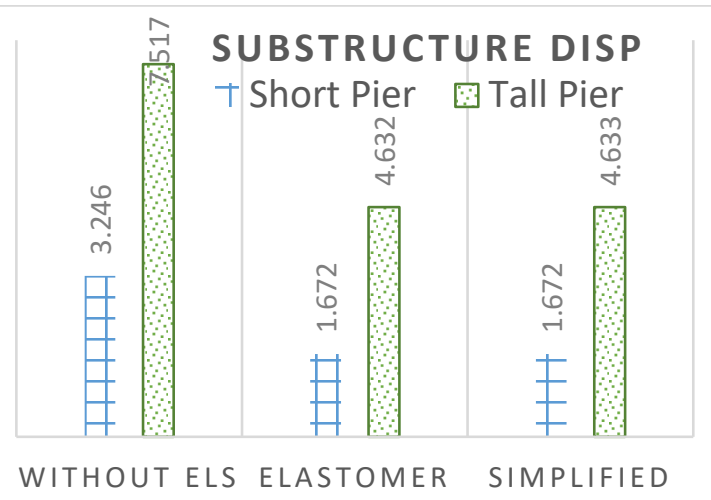

Figure 12c. Substructure Displacement Comparison

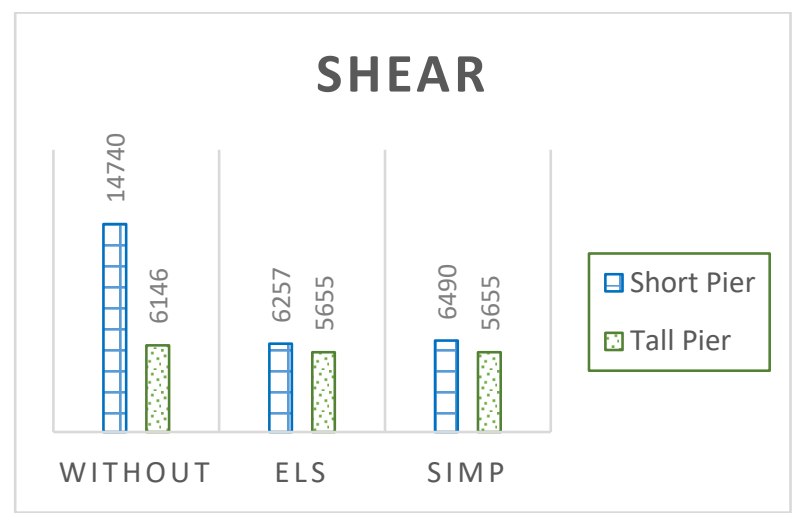

Figure 12b. Base Shear Comparison at the Piers

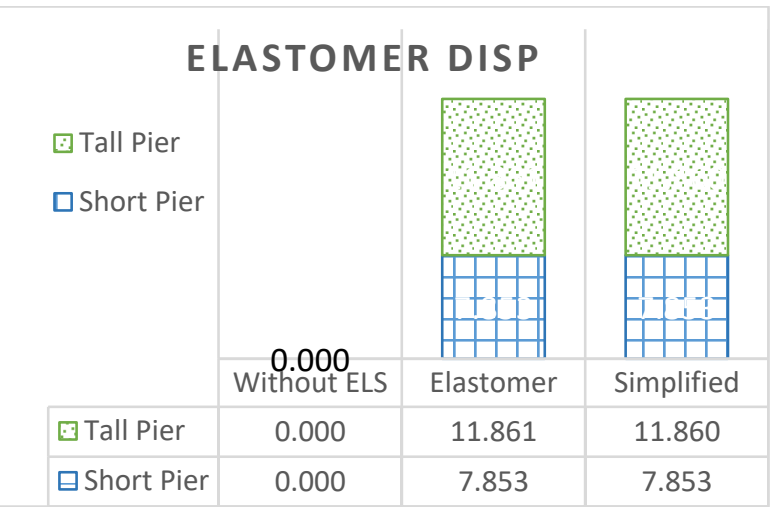

Figure 12d. Elastomer Displacement Comparison 
INTERNAL FORCES RATIO

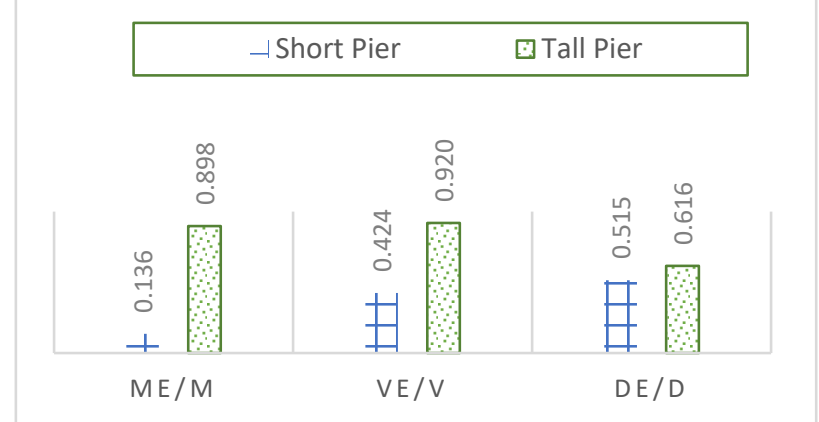

Figure 12e. Amount of Internal Force Comparison

\section{Conclusion}

For investigating, the effects of elastomeric bearing on the example Shurun-Urgun Composite Steel Bridge both multi-mode and simplified (SDOF system) analyses have been considered in computer models in cases of considering and ignoring the elastomeric bearings properties. Fundamental period shifts, displacements and changes in internal forces distribution in bridge members have been examined, also to precisely come to show effect of substructure rigidity on seismic response, same bridge with taller but flexible piers is analyzed.

Positive reasons from this investigation show that elastomeric bearings have a positive response against the seismic forces applies on the bridge that immensely relies on geometry of bridge, particularly the pier rigidities. Elastomeric bearings for bridge with short piers by absorbing applied forces and appropriately lateral loads between piers and abutments reduce base shear of bridge about $58 \%$, moment about $86 \%$, and $52 \%$ in displacement. On the other hand, comparing results with bridge with tall piers in which reduction of base shear is about $8 \%$, moment about $10 \%$ and displacement about $38 \%$. In addition, elastomeric bearings increase fundamental period, of the time that bridge undergoes one complete cycle of oscillation, of bridge with short piers about $14 \%$ more than bridge with taller piers. Consequently, elastomeric bearings in generally for all bridges and specifically bridges with short piers are effective.

Elastomers by absorbing applied forces cause extra displacement of substructure increase displacement of substructure. It becomes more significant if the height of piers increases. Despite, the numerical investigations reveal the positive affect of elastomeric bearing in seismic response, it is highly dependent on geology of bridge, and pier rigidity.

\section{References}

AASHTO. (2012). AASHTO LRFD Bridge Design Specifications. Washington, DC: American Association of State Highway and transportation Officials.

Bird, P. (2003). An Updated Digital Model of Plate Boundaries: G3, geochemistry, Geophysics, and geosystems. v. 4, p. 1- 52.

Boyd, O., Mueller, C., \& Rukstales, K. (2007). Preliminary Earthquakes Hazard Map of Afghanistan. Virginia: U.S. Geological Survey.

Caltrans. (1994). Memo to designers 7-1, Bridge Bearings. Sacramento, California: California Department of Transportation.

Caltrans. (April 2000). Bridge Design Specification. In Section 14 - Bearings (p. 16p.). Sacramento: California Department of Transportation. 
Caltrans. (June 1994). Memo to Designers. Sacremento, California: California Department of Transportation.

Caltrans. (November 2010). Section 5 - Analysis. In Seismic Design Criteria Version 1.6 (pp. 53-59). Sacramento, California: California Department of Transportation.

Caltrans(Metric). (October 1995). Bridge Design Practice. Sacramento, California: California Department of Transportation.

Chen, W.-F., \& Duan, L. (Eds.). (2000). Bridge Engineering Handbook. CRC Press.

CSI. (1978-2011). SAP2000 Ultimate 15.1.0. Berkeley, CA.: Computers and Structures, INC.

FHWA. (2006). Seismic Retrofitting Manual for Highway Structures: Part 1- Bridges. Federal highwy Administration.

Jade, S. (2004). Estimates of Plate Velocity and crustal deformation in the Indian Subcontinent Using GPS Geodesy. v. 86, pp. 1443-1448.

Ruleman, C., Crone, A., Machette, M., Haller, K., \& and Ruskstales, K. (2007). Map and Database of Probable and Possible Quaternary Faults in Afghanistan. :U.S. Department of the Interior. Reston, Virginia: U.S. Geological Survey. Retrieved from https://pubs.usgs.gov/of/2007/1103

Sella, G. D. (2002). REVEL - A model for recent plate velocities from space geodesy. Journal of Geophysical Research, v. 107(B4). doi:10.1029/2000JB000033

Vernant, P. N. (2004). Contemporary Crustal Deformation and Plate Kinematics in the Middle East constrained by GPS measurements in Iran and north Oman. Geophysical Journal International, v. 157, p. 381- 398. 